\title{
Ciudadanía y participación
}

\author{
Ramiro Fernández ${ }^{1}$
}

\begin{abstract}
Resumen
En el presente artículo se pretende abordar los temas de ciudadanía y participación, presentando una visión respecto de cómo la participación, en este caso juvenil, se distancia de las concepciones tradicionales establecidas para el ciudadano desde la institucionalidad, y genera nuevos espacios que posibilitan formas alternativas (los otros) de constituir ciudadanía, distanciándose de las visiones "puristas" respecto de la participación ciudadana
\end{abstract}

Palabras clave: Ciudadanía, Juventud, Participación, Democracia.

\begin{abstract}
This article seeks to address the issues of citizenship and participation, presenting a vision for how participation in this case youth, distances itself from traditional concepts established for citizens from the institutions, and creates new spaces that allow alternative forms (the others) to establish citizenship, moving away from the visions "purists" for citizen participation
\end{abstract}

Key words: Citizenship, Youth, Participation, Democracy.

1 Sociólogo, egresado de la Universidad Católica Silva Henríquez. 


\section{Introducción}

Haciendo una introducción a la noción de ciudadanía, podemos entenderla como la ecuación de las virtudes (producción de subjetividades) de los ciudadanos que asimismo, el bien común es político y lo encamina y constituye la sociedad junto con su institucionalidad (Estado). La problemática se plantea ya que hoy la institucionalidad es sobrepasada por las virtudes de los ciudadanos que buscan el bien común.

Como se tiene en la memoria al Estado benefactor, la sociedad civil se organiza en torno de demandas sectorizadas y particulares fundamentadas en los intereses colectivos del sector, a partir de esta organización es que se consolida la participación ciudadana. Es así como la sociedad civil actual, si bien participa de la misma forma, hay un sector, que emerge principalmente en la juventud, el cual opera bajo otros intereses que también son particulares y sectoriales, pero que se encumbran en el bien común en tanto deseo común por lo cual la ciudadanía o la calidad de ciudadanos no es posible de ser significada de la forma tradicional.

El Estado benefactor, y el Estado como posibilidad de organización de las virtudes y necesidades ciudadanas, ha perdido los espacios de acción y por lo mismo también la eficiencia, en sentido de la capacidad de convocar la producción de subjetividades y necesidades colectivas e individuales que llevaron a su conformación y que lo hacía necesario, como punto de recurrencia ineludible de la ciudadanía.

En los 90 el peso de la sociedad civil es menor, entonces la institucionalidad democrática funciona como una democracia elitista donde son los partidos políticos quienes mandan la agenda pública. Hoy la sociedad civil está más organizada y participa con algunos de los códigos heredados de los movimientos sociales (revueltas, manifestaciones estéticas, llamamientos a los descontentos colectivos); lo que cambia es a nivel de su orgáni- 
ca, la estructura se constituye sobre una lógica de asambleísmo (pretensión de horizontalidad). Tal es el caso de la "rebelión del coro", referida al movimiento estudiantil de mayor alcance en Chile, donde los estudiantes secundarios dejaron de manifiesto la posibilidad latente de dejar en "jaque" la institucionalidad desde una organización que permitió obtener representatividad en la ciudadanía. Aun cuando el Estado logra resolver y controlar estos eventos no sin costos importantes dentro de los parámetros de la política tradicional, la potencialidad expresada por este movimiento colectivo está dada desde el deseo de construir otras formas de participación.

Las nuevas formas de participación se fundan en distintas acciones colectivas e individuales que buscan el bien común. El tema está en que los dispositivos de participación son más amplios que los que manejan la estructura política formal de participación, ya que el elemento legal del voto es dejado en segundo lugar por el elemento sociocultural de la voz. Por lo tanto, la ciudadanía actual no puede ser reducida en el espectro esencialmente legal, sino que debe ampliarse al social-cultural, en donde la forma de ejercer ese derecho a voz, es más universal incluso que la del voto, si bien no tiene efectos directos sobre la estructura política, cuando se visualiza adquiere una importancia significativa.

Es el espacio de la juventud donde, a nuestro juicio, emergen con mayor frecuencia y visibilidad estas nuevas formas de participación y por tanto de concebir la ciudadanía. Debemos entender la juventud no como un tramo etario establecido por la institucionalidad para demarcar los procesos que deben sucederse en el transcurso de la vida, construcción que viene dada desde las visiones más positivistas, sino como un estadio que dice relación con una visión inquisitiva, en distintos niveles, respecto de lo establecido, por lo general una visión crítica y disconforme con aquello que "está dado", podríamos enunciarlo como un espacio de transformación, un espacio por lo general reducido en 
términos de amplitud (poco tiempo, aunque relativo e ilimitado), lo que otorga un mayor potencial en el sentido de satisfacer ese deseo de transformación.

Un antecedente respecto de la carencia que presentan los medios de participación tradicional en los jóvenes tiene que ver con la evolución de los porcentajes de electores inscritos entre 18 y 29 años para los procesos electorales, que va desde el plebiscito de 1988 hasta la presidencial del 2005, con el siguiente desarrollo:

Cuadro 1: Evolución de los porcentajes de electores inscritos entre 18 y 29 años

\begin{tabular}{|c|l|c|}
\hline Año & Elección & \% respecto del total inscritos \\
\hline 1988 & Plebiscito & $72 \%$ \\
\hline 1989 & Presidencial y Parlamentarias & $67 \%$ \\
\hline 1992 & Concejales & $60 \%$ \\
\hline 1993 & Parlamentarias & $57 \%$ \\
\hline 1996 & Concejales & $45 \%$ \\
\hline 1997 & Parlamentarias & $40 \%$ \\
\hline 1999 & Presidenciales & $32 \%$ \\
\hline 2000 & Concejales & $29 \%$ \\
\hline 2001 & Parlamentarias & $26 \%$ \\
\hline 2004 & Alcaldes y Concejales & $18 \%$ \\
\hline 2005 & Presidencial & $19,45 \%$ \\
\hline
\end{tabular}

Fuente: www.servel.cl

Con este antecedente, damos cuenta de un fenómeno ya conocido y bastante discutido en la contingencia nacional, y que tiene que ver con la disminución sostenida de la participación de los jóvenes en los canales tradicionales de manifestación política, entendiendo las elecciones, y los procesos electorales, como la piedra angular de los sistemas democráticos, sobre la cual al parecer los jóvenes ya no sustentan sus formas de acción, lo que no indica, como desarrollaremos en el presente artículo, que no se "expresen" políticamente, sino que nos remite a un vuelco en el eje de participación ciudadana desde la juventud, donde los canales formales ya no son los que satisfacen las necesidades de participación política, específicamente, juvenil. 
Un segundo antecedente que complementa lo enunciado anteriormente, dice relación con las formas de participación política que "prefieren" o satisfacen a los jóvenes actualmente. En este sentido vemos el creciente impacto que han tenido las marchas y manifestaciones masivas por parte de diversos sectores, secundarios, universitarios y grupos juveniles que se reúnen en torno a motivaciones de corte cultural, presentando una fuga respecto de los canales de participación política más tradicionales e imperantes, y que tienen que ver con la adhesión a los partidos y la inscripción en los registros electorales.

Con esto no pretendemos señalar que los jóvenes no se integren dentro de las formas tradicionales, por lo general los dirigentes de los grupos de estudiantes sí tienen participación desde el punto de vista tradicional de la militancia partidista, sin embargo lo que potencia a los distintos "movimientos" (en tanto eventos), está dado porque sus demandas e intereses se desprenden y desplazan de los intereses estructurales o molares de la ya des-legitimada política tradicional.

\section{Ciudadanía}

Ahora bien, para entender el modelo actual de participación al cual asistimos desde las manifestaciones políticas juveniles, es necesario remitirnos al concepto de ciudadanía, el cual constituye la política tradicionalmente entendida, además que sirve para, por defecto, entender también estas nuevas formas en tanto no responden a las clasificaciones formales de ciudadanía. Dicho de otro modo, no entienden al ciudadano desde la lógica política molar, sino que en términos de su especificidad molecular.

Dentro de la teoría política no existe un consenso sobre la composición de lo que se denomina ciudadanía, debido principalmente a que no se establecen convenciones generales al respecto, ello en gran parte se ve acrecentado en el hecho de que en cada posición política -como construcción teórica- se establece el rol del individuo a sus ópticas particulares; es así como nos en- 
contramos con diversos desarrollos teóricos que dan cuenta de lo anterior y dentro de ello podemos mencionar la concepción de la ciudadanía liberal, la republicana, democrática, comunitarista, entre otros. Estas dimensiones teóricas no son puras sino que en la práctica la instrumentalidad las lleva, muchas veces, a fundirse en democrática/liberal, democrática/republicana, republicana/ comunitarista.

Entonces cuando nos referimos a ciudadanía debemos desentrañar que se debe entender la posición desde la cual se está estableciendo la distinción, de otra manera este ejercicio sería infructuoso. Consiguientemente entenderemos que la ciudadanía se refiere a los modos de participar y acatar tanto derechos y deberes dentro de un sistema político, sea democrático, liberal, etc.

Remontándonos a los primeros fundamentos de lo existente en teoría de la ciudadanía debemos llegar a Aristóteles, desde allí encontramos visiones concretas sobre el ser ciudadano; por ejemplo, ser ciudadano para Aristóteles es integrar un Estado de características democráticas, no excluyendo el hecho de que esto pueda existir en uno no democrático, pero supone que no es necesariamente así, ya que el fundamento de la democracia sería la condición de su pueblo y ello está en directa relación con la práctica de la ciudadanía, y en consecuencia de las características de la constitución es decir de su cuerpo legal. También se menciona la virtud de participar en la asamblea pública y hacer valer la voz y el voto. Pero no sólo son un conjunto de valores en el marco legal de participación en lo público, sino que también se hereda desde el mundo privado, como lo que respecta a la familia, ya que algunos pueden ser considerados ciudadanos sólo si ambos padres lo son.

Con esto se introduce una variable nueva al concepto de ciudadanía que escapa al marco legal y se ubica dentro de la dimensión temporal, en tanto quien pudiera probar que su ascendencia era mayor en términos de ciudadanía podría querer establecer 
algún tipo de privilegio de ello. De esta forma Aristóteles se pregunta por la legitimidad de ser considerado ciudadano, más allá de cumplir las condiciones, y por otro lado nos lleva a revisar la ciudadanía desde la función y la estructura.

Si el Estado es efectivamente una especie de asociación; si es una asociación de ciudadanos que obedecen a una misma constitución, mudando esta constitución y modificándose en su forma, se sigue necesariamente, al parecer, que el Estado no queda idéntico; es como el coro que, al tener lugar sucesivamente en la comedia y en la tragedia, cambia para nosotros, por más que se componga de los mismos cantores. ${ }^{2}$

Es decir, que la concepción de ciudadanía también puede ser vista como parte del complejo sistema de un Estado, donde la ciudadanía es parte de la función de un Estado, no por sí sola, pero en gran medida, y es así como la ciudadanía es una virtud, como lo menciona en la analogía del marinero, todos desde su particular función buscan que el barco llegue a buen puerto. Pero cosa distinta es lo concerniente al ámbito privado y lo público, y aquí cabe la pregunta de si la ciudadanía es sólo una virtud pública.

De otra forma lo político es el medio por el cual los ciudadanos buscan el bien común -buen puerto-, por lo tanto la búsqueda de éste debe y es una virtud pública, pero que no tiene directa relación con la vida privada, aunque podría darse; no es condición absoluta, ya que si bien se busca una virtud común (identidad) para el hombre no es adecuado que todos posean su virtud privada, de otra forma perdería su fundamento de privada.

Además hace la distinción de la virtud del ciudadano que es fruto del ejercicio de su visión del bien común, y de la virtud general que es la suma de las virtudes de los ciudadanos, y por ello no son idénticas, reconociendo la capacidad heterogénea de

2 Aristóteles, Política, Libro tercero, Del Estado y del ciudadano. Teoría de los gobiernos y de la soberanía. Del reinado. Capítulo I Del Estado y del ciudadano en: http://ar.geocities.com/proyectoinacayal/cuerpo_BibliotecaInacayal.html 
los ciudadanos, es decir existen distintos ciudadanos y sus virtudes, pero existe una ciudadanía y su virtud, y no es condición necesaria que sean lo mismo, así como tampoco hay similitud entre quien gobierna a la ciudadanía y quien ejerce el ejercicio particular de la ciudadanía.

Pero si el mando debe ser patrimonio del hombre de bien, y el saber obedecer y el saber mandar son condiciones indispensables en el ciudadano, no se puede, ciertamente, decir que sean ambos dignos de alabanzas absolutamente iguales. Deben concederse estos dos puntos: primero, que el ser que obedece y el que manda no deben aprender las mismas cosas; segundo, que el ciudadano debe poseer ambas cualidades: la de saber ejercer la autoridad y la de resignarse a la obediencia ${ }^{3}$.

Es manifiesto que la virtud de ser ciudadano no es la misma de la magistratura. En este sentido, y recurrentemente en Aristóteles, queda de manifiesto que la universalidad del concepto de ciudadanía no es restringido de forma que se pretenda moldear al hombre a ciertas virtudes, sino que entiende que existen diferentes hombres y que a ellos el bien como la responsabilidad cívica les es asimétrica, por lo que establecer un complejo sobre lo que es en sí la ciudadanía resulta de una serie de elementos, inclusive la edad. Los niños y los ancianos no son ciudadanos en forma absoluta y los últimos dejaron de serlo y los otros en lo porvenir. Entonces, antes, para la concepción de ciudadanía existen ciudadanos diversos y que en sí mismos son heterogéneos. En otro sentido, no todos los hombres que habitan en la ciudad y que son libres son ciudadanos, sino que es plenamente ciudadano cuando se participa en los poderes públicos, y que:

“... la discusión precedente ha demostrado en qué la virtud del hombre de bien y la virtud del ciudadano son idénticas, y en qué difieren; hemos hecho ver que en un Estado el ciudadano y el hombre virtuoso no son más que uno; que en otro se separan; $y$, en fin, que no todos son ciudadanos, sino que este título pertenece sólo al hombre político, que

3 Ídem 
es o puede ser dueño de ocuparse, personal, o colectivamente, de los intereses comunes." ${ }^{4}$

Por tanto la ciudadanía como fundamento es una virtud de lo político, en tanto parte del bien común que es el centro de lo político en la visión aristotélica.

\section{Ciudadanía y democracia}

Dentro de lo que denominamos política tradicional nos encontramos con la interpretación que se condice con la democracia elitista, que siguiendo a Cohen y Arato (2000), es la que dice relación en uno de sus ejes explicativos, con el hecho que no es sobre un tipo de sociedad, modelo o paradigma, sino más bien un "método" por el cual se elige a los líderes políticos.

Lo cual desemboca en que la estrategia de poder se vincula en aceptar que el fundamento político viene del poder y la lucha por él, es el centro de la política. A su vez se trata de un método que podríamos denominar como una relación lineal, ya que tanto la agenda como las decisiones políticas se toman desde las esferas del poder, "más bien los líderes (partidos políticos) agregan los intereses y deciden cuáles van a ser más relevantes políticamente... los votantes son consumidores" (Cohen y Arato, 2000:5). Por tanto esta relación lineal, sólo permite como vehículo de cambio y transformación social, la posibilidad de que una demanda o programa paralelo debe formalizarse dentro de este modelo elitista para incidir y seducir a los "votantes consumidores". Por tanto estamos en presencia de un método de mercado, nos aventuramos a decir que la política es formulada como una industria, la cual se le transfiere a la sociedad como un elemento más de consumo, y la ciudadanía queda referida sólo a un momento que pre-establece el bien común, entonces lo público no es virtud del ciudadano sino virtud de una elite.

4 Ídem 
Por otro lado la política normativista cree que la solidez y estabilidad de la sociedad no está justamente en lo que la constituye como democrática, porque sus procedimientos democráticos no son lo suficientemente "libres" en tanto son impuestos, y no representan una voluntad discursiva, porque rompe los códigos de la democracia en tanto ciudadanía, ya que es una relación de poder entre las instituciones políticas y la ciudadanía y no una correlación de poder entre ellas, donde esta última debiera tener un rol representativo.

Los liberales, más bien el modelo liberal, por su parte, frente a estas líneas se preguntan si la libertad podría existir en un mundo moderno, y si los derechos individuales y normas de una comunidad explican y fundamentan la libertad, a partir de que "los individuos como tales tienen derechos morales que funcionan como limitaciones sobre el gobierno y sobre otros" (Cohen y Arato, 2000:9). Se podría argüir que la concepción de una moral universal categórica al estilo Kantiano impondría por convención el bien público, pero su carencia es que los individuos y la sociedad y por consiguiente la política no es una estructura preexistente sino que es el hombre un sujeto portador de historia.

En este sentido, es aquí donde se legitima la concepción de justicia en tanto universalista, dado que la premisa liberal dispone de un sujeto autónomo libre y creativo, lo cual es el supuesto esencial para el modelo de libre mercado, donde los sujetos son libres competidores a partir de su iniciativa.

Pero de la misma forma se introduce en decir que el hombre nace libre y con las mismas capacidades para competir, pero el aspecto socio-histórico nos indica que no es así, sino que el hombre hereda ciertas condiciones que frenan su autonomía y su habilidad para crear y poder competir, por lo cual se presenta a una ciudadanía heterogénea, donde si bien el bien común es por convención estatuido como universal, la entrada y participación en ello es asimétrica históricamente. 
Por otro lado, los comunitaristas arguyen que tales presupuestos individuales son contradictorios con la libertad, en tanto ésta es esencialmente positiva y no restringida; para ello utilizan una argumentación socio-histórica en tanto su entrada al mundo ocurre con un proceso de aprendizaje a las normas socioculturales, como lo es la socialización, lo cual confiere una mayor atención epistemológica con lo empírico que con una racionalidad abstracta como los liberales. A su vez, la pretensión universalista no es tal ya que "El individuo no puede tener una base firme para hacer juicios morales sin obtenerla de una comunidad con la cual está comprometido" (Cohen y Arato, 2000:10). En este sentido se acercan a la concepción de que el individuo es tan sólo en sociedad y por tanto su libertad está en relación con el conjunto de herencias morales, y así con la virtud de lo cívico.

Dentro de la misma línea de la política tradicional, pero con un carácter distinto están las teorías que apuntan al Estado como centro neurálgico de la formación política. Los defensores del Estado benefactor observan como una de sus virtudes, el derecho legal a los servicios estatales y la supresión de los conflictos sociales, ya que subsidia los efectos del mercado. Ayudado porque le confiere un papel central a la sindicalización como herramienta de negociación colectiva.

Esto está relacionado en la conjunción de las organizaciones civiles con los partidos políticos y sus representaciones sindicales, como vehículos que agrupan y canalizan las inquietudes y demandas de la sociedad civil, para presentarlas al Estado.

En este sentido el ciudadano tiene el apoyo institucional para ejercer en lo público sus demandas y poder contribuir al bien común, sin embargo, la visión del bien común queda remitida a la posición que tienen ciertos sectores que empujan hacia un bien común que puede estar basado en virtud de lo público pero que se presenta sesgado ya que responde a intereses de clases y de ideologías. No viendo el aspecto negativo en ello, ya que rompe 
la convencionalidad moral individual, pero se sitúa como una búsqueda sectorizada que se agudiza con el advenimiento de la clase media, que de alguna manera al tener puentes más directos de diálogo con el poder dirigente rescata parte de la virtud de la ciudadanía en tanto pública que nos mencionaba Aristóteles; aquí podemos encontrar a los grupos de interés.

En tanto el neoconservadurismo cita como uno de los mayores problemas las virtudes antes mencionadas, ya que impulsan conflictos partiendo de la intromisión del Estado en áreas políticas y económicas que pertenecen al sector privado -o que funcionarían mejor desde este sector-, coartando las oportunidades de los empresarios y los incentivos de los trabajadores, honrando el fracaso en vez de la superación.

Así el neoconservadurismo construye a la ciudadanía, y ésta quedaría remitida nuevamente a un momento instrumental que escaparía al bien común construido por el hombre de bien, sino que se concentraría en la producción del bien común como un final que se desarrolla desde la particularidad de las relaciones económicas y productivas y no desde las cualidades del ciudadano per se, con lo que la ciudadanía es el efecto de la participación en las formas economicistas de la vida pública; aquí se resalta el carácter privado de la ciudadanía que exponía Aristóteles, ya que quienes podrían participar con mayor propiedad en este modelo político y de ciudadanía o quienes tendrían el control de esto, serían efectivamente los que de alguna forma han heredado un piso sólido por el cual permanecer, desde la propiedad privada, en una posición política favorecida.

Por otra parte el pluralismo democrático cimentado en la figura de Tocqueville, se nutre de la real posibilidad que tienen los ciudadanos en la participación activa dentro de las instituciones y las asociaciones civiles, fundadas en el criterio del bien común como voluntad política colectiva (Cohen y Arato: 2000). Según estos autores, la democracia radical plantea que la participación 
ciudadana, utilizando la herramienta del movimiento social, debería remplazar los acuerdos institucionales de un sistema democrático representativo.

Por tanto la predominancia del carácter legal de ciertas distinciones de la ciudadanía, como por ejemplo la liberal, y por otro lado el normativo y el comunitarismo democrático, no serían teóricamente contradictorias y por ello son complementarias, y de esta manera se adentran en considerar una nueva forma de sociedad civil, con características pluralistas tradicionales y con participación de la ciudadanía dentro de las esferas públicas sin mezclar lo privado, ya que entienden una separación del mundo social y del mundo económico, que es a su juicio, la confusión que ha entorpecido la real concreción de un sistema democrático, fuere cual fuere. Además creen que la democratización de la sociedad civil necesariamente ayuda a abrir las estructuras de los partidos políticos (salida a los PP tradicionales), por esto, resulta interesante la visión de Cohen y Arato que ven en la ampliación de las estructuras, más bien dicho en la ampliación y dilatación de los límites de los sistemas democráticos, una nueva forma de sociedad civil que reencarnaría al hombre político en la participación de un sistema político democrático que les es un tanto ajeno hoy en día, y especialmente, facilitaría las herramientas para la participación de los sectores que se encuentran en los límites del sistema, siguiendo a Melucci (1994).

Lo cierto es que es un buen ejercicio para el juego democrático reparar estos sitios de encaje, pero sería mejor comprender que existen sectores que no son anomalías del sistema y que su posición es parte de un contenido político en tanto decisional comunicativo, simbólico, y es ese fenómeno, creemos, el que no ha sido entendido, ya que se trata de volver, re-descubrir, refundar, el tema político desde los parámetros de participación y ciudadanía que el lenguaje político reconoce, y hoy por hoy la ciudadanía debe ser pensada no tan solo como insertada en el juego sino también en la posibilidad de que practique otro juego, por ejemplo el 
de ciertas manifestaciones estéticas, informacionales, de la vida cotidiana con claros componentes culturales, que no se recogen en las tradicionales concepciones de ciudadanía política.

Una posición más radical, que versa sobre la falta o agotamiento de una ciudadanía, la da Lipovetsky (1996): dentro de su particular planteamiento funda el problema actual de la ciudadanía en que esta última sólo se ve reflejada como la "preponderancia de los derechos individuales sobre las obligaciones colectivas." (Lipovetsky, 1996:202).

En este sentido el diagnóstico que este filósofo hace sobre la sociedad contemporánea se traslada al concepto de ciudadanía, ya que el carácter individualista de la sociedad minaría los principios universales de la ciudadanía liberal. Entonces se estaría en presencia de una pérdida de jerarquía de lo que se denomina bien común, tanto como de los aspectos legales, por lo cual "estas son más democracias de individuos que democracias de ciudadanos." (Lipovetsky, 1996:203). Así la participación se centraría en un recurso particular, sobrevalorando los aspectos negativos de los deberes y la libertad, ya que la ética posmoralista sitúa al individuo dentro de un bombardeo de información donde ve que su tranquilidad y bienestar son puestos en peligro por ciertos sectores que persiguen equivocadamente fines colectivos.

Por tanto se recurre a la recuperación de las concepciones más básicas de la moral, la lealtad, la honestidad, el no causar mal a otro individuo. En este sentido el horizonte moral de los individuos es reducido a los fines particulares y no se consiguen los principios del bien común que cruzaban los componentes de la ciudadanía en tanto política, desde aquí la ciudadanía se trasforma en un aspecto más de la propiedad privada, ya que todo aquel que no se nos presente dentro de esa reducida moral, puede ser justamente castigado por los mecanismos legales, anteponiendo solo el bien personal y no el de la colectividad; pareciera ser que aquellos que ven ofendidas sus particularidades, las defienden 
con una fuerza mayor que con la que defienden los bienes de toda una comunidad.

"Cuando la ética prometeica de mejoramiento del género humano está caduca, queda la ética mínima de la honestidad, de la transparencia y de la reproducción democrática, que, como es sabido, se encuentra ya integrada en las estrategias de marketing de las promociones políticas de los media." (Lipovetsky, 1996:205).

Otra lectura sobre la ciudadanía, que presenta o parte de un desencanto con los actuales marcos comprensivos de la ciudadanía y de lo político en general, la muestra Chantal Mouffe (1999); ella comienza del desencanto sobre el fracaso del proyecto de izquierda como un vehículo válido para generar cambios en las sociedades, a partir de las relaciones sociales como producto político, y a su vez, plantea la necesidad de radicalizar las formas de institucionalización de lo político partiendo por la profundización de los ideales democráticos como la participación y la solidaridad. Para ello entiende que la idea del liberalismo de universalizar lo político a partir del imperativo categórico kantiano, deja la ciudadanía en el espacio de lo legal, menospreciando otros aspectos como la participación y lo cívico. Por tanto la libertad del ciudadano sólo es vista como una característica negativa y no podría ser de otra manera, ya que el bien común no es propicio para las actuales democracias, lo que relega a la participación en el sistema democrático, cualquiera sea su apellido, a un plano meramente ficticio.

A esta discusión se oponen, según Mouffe, los comunitaristas que proponen tomar la libertad como una construcción sociocultural y no meramente legal, ya que el bien común no está bajo el derecho, por lo cual existiría una disociación entre lo político y lo ético, y es en este punto donde Mouffe cree que se ha extraviado el real sentido de lo político, para ella no existiría una separación abierta entre los derechos y la libertad individual. Siguiendo a Wittgenstein, Mouffe plantea la gramática de la política que es 
un principio de libertad política y "ser ciudadano es reconocer la autoridad de tales principios (de libertad) ${ }^{5}$ y las reglas en que se encarna, hacer que sean ellos los que den forma a nuestros juicios y a nuestras acciones... este es el significado de ciudadanía que yo quisiera proponer... implica no considerar la ciudadanía como un estatus legal sino como forma de identificación, un tipo de identidad política: algo a construir, no dado empíricamente". (Mouffe, 1999: 96). En este sentido la ciudadanía es un porvenir, y no un pretérito, con lo cual se está construyendo permanentemente con el concurso de la comunidad política, de los ciudadanos, un nosotros, una identidad.

"La creación de las identidades políticas como ciudadanos democráticos radicales depende, pues, de una forma colectiva de identificación entre las exigencias democráticas que se encuentra en una variedad de movimientos: de mujeres, de trabajadores, de negros, de gays, de ecologistas, así como en otros <nuevos movimientos sociales>" (Mouffe, 1999:102).

Desde aquí se entiende que la ciudadanía se conoce como un elemento que rescata los ideales republicanos participación y los nutre de las nuevas formas de participación, tomando sectores de la sociedad que podrían considerarse por fuera del sistema formal de participación, entonces a partir de ellos reconocemos que también se engarza la posibilidad de que en lo público se presenten aspectos que vienen de la vida privada y que trascienden a lo público, por cuanto nuestra posición frente al carácter estético de la acción colectiva está sintonizado, creemos, con el planteamiento de ciudadanía que propone Mouffe, sobre todo porque nos impulsa a trabajar en pos de una re-configuración de lo político; no hablamos de una nueva política sino de una resignificación de lo político.

Pensándolo desde los marcos posmodernos que nos invitan a dar una mirada más profunda a los aspectos del lenguaje y lo cultural, y por ellos el plantear la ciudadanía como una perma-

$5 \quad$ Negritas nuestras. 
nente construcción política que a nuestro juicio deriva de ciertos aspectos culturales que se profundizan en sectores como la juventud y en sus formas de participación, tales como las estéticas y las virtuales.

\section{Cómo la institucionalidad reduce la ciudadanía.}

Entonces la ciudadanía es la suma de las virtudes particulares, "deseos" que se manifiestan en el ordenamiento institucional de la ciudadanía, que en términos actuales se denomina sociedad civil. La complejidad de entender que la institucionalidad responde actualmente a esta sociedad civil está dada porque el Estado concibe tanto la ciudadanía como a la sociedad civil como uno solo, es decir, que el marco regulatorio que el Estado y la institucionalidad aplican, tiene definidos los límites de la participación para la sociedad civil; la disyuntiva se da cuando la sociedad civil busca y crea otros canales "fugas" de participación que no responden al instaurado por la institucionalidad, siguiendo a Weber en un tipo ideal. Por otro lado este tipo ideal no es tal ya que la concepción de ciudadanía no es el resultado final de la suma de las virtudes y deseos particulares, sino es la ecuación entre las distintas virtudes y deseos de los sujetos. Estos deseos son políticos en cuanto se enmarcan dentro de la estructura definida desde la institucionalidad, que va más allá del Estado, que encuentra diversas manifestaciones como el mercado, lo estético, lo artístico. Sin embargo, la construcción de esta ciudadanía desde los deseos particulares de los sujetos, trasciende sustancialmente el marco establecido por la institucionalidad.

Esta reducción del concepto de ciudadanía, y en definitiva de la participación política, no debe ser entendida como una "falla" del Estado en la construcción de su marco estructural, sino que se presenta como una condición de la institucionalidad en la configuración de los ejes "regulatorios" y "reduccionistas" de los espacios sobre los cuales la participación es legítima. La contrariedad se presenta cuando nos encontramos con constantes pun- 
tos de tensión que dan cuenta de lo incompleto de estas definiciones y limitaciones, las cuales no satisfacen el deseo ciudadano -no respondiendo a la virtud política de los agentes políticos- de participación y sobre el cual emergen nuevos eventos que se desprenden de la institucionalidad, y que tienen la problemática de sortear estas deslegitimaciones a partir de la aparición constante que da cuenta de sucesos que trascienden la idea de una anomalía, y que se presentan como nuevas formas de expresión que aspiran a esa validez, pero no pretendiendo insertarse dentro del marco institucional, sino que por fuera de éste.

Aquí nos encontramos frente a una nueva problemática, y que tiene que ver con el momento en que la institucionalidad, a la luz de estas constantes contradicciones entre el deber ser establecido y la realidad de la participación, integra o pretende "cooptar" las formas emergentes de participación social y política, situación que en la actualidad parece estar estancada desde el punto de vista de la atadura que encuentra la institucionalidad respecto a la unívoca visión de participación política ciudadana actual y que, al parecer, y a la luz de los antecedentes, no es lo suficientemente completa en relación con las formas de expresión actual. Por lo cual cuando las movilidades políticas son diversas, el Estado responde tardíamente a ellas, en cambio al mercado, por ejemplo, le resulta más fácil cooptar estas nuevas expresiones, que no se limitan al mercado solamente, sino que además se amplían a escenarios más masivos e invisibles como los referidos al plano cultural.

Al mercado se le toma como ejemplo, pero no es idea poner frente a frente al Estado y al mercado respecto de cómo toman y responden al concepto de participación, sino solo para dejar de manifiesto una deficiencia de la institucionalidad política actual. En síntesis enunciamos como el capitalismo, a partir del mercado, consume la política, y el Estado no sabe responder a ello, y que la sociedad civil busca salidas, las cuales no son codificadas correctamente por el Estado. 
El quiebre entre el Estado y las respuestas que debiera tener para estas nuevas formas de participación está dado porque el Estado, carece efectivamente de una respuesta a tiempo, es decir de celeridad en su reconfiguración. Este retraso es propio de una institucionalidad como el estado. Por otra parte, es este, el Estado, el que en un momento regulaba el ritmo de los mercados, pero que actualmente le es imposible hacerlo y por ello solo debe responder y no es proactivo, por lo cual siempre llega tarde y cuando debe tomar medidas para ello, la gran mayoría de las veces deslegitima las acciones políticas que no están dentro de lo que él como institucionalidad entiende y ha conformado como ciudadanía.

Desde Marshall podemos inferir tres estadios de ciudadanía que se presentan a continuación a modo de introducir esquemáticamente la noción de ciudadanía desarrollada más adelante.

\begin{tabular}{|l|l|l|}
\hline Civil & Político & Social \\
\hline $\begin{array}{l}\text { Libertad individual } \\
\text { (tribunales de justicia) }\end{array}$ & Participación (voz y voto) & Bienestar económico \\
\hline $\begin{array}{l}\text { Nace de la burguesía ya } \\
\text { que es fundamental para } \\
\text { el libre mercado }\end{array}$ & Parlamento & Seguridad \\
\hline Defienden la propiedad & $\begin{array}{l}\text { Sufragio universal no } \\
\text { siempre }\end{array}$ & Igualdad \\
\hline Siglo XVIII aristócrata & Fraternidad & Educación \\
\hline Siglo XX & $\begin{array}{l}\text { Siglo XX clase media } \\
\text { industrial }\end{array}$ & Siglo XX clase obrera \\
\hline
\end{tabular}

Fuente: Elaboración propia

A partir de esta codificación de cómo se debe entender la ciudadanía desde su visión más tradicional, existe también su difusión a partir de los tipos de democracia distinguidos por Cohen y Arato. Donde se puede enmarcar la democracia elitista, como la referida principalmente al tipo de ciudadanía civil aristocrática, fundada en principios judicialistas y de defensa de los derechos individuales y la libertad. Así también la democracia participativa encuentra su representación en un enfoque de ciudadanía 
política, donde el parlamento es el espacio de mayor representatividad y el voto expresa los deseos de los ciudadanos, esgrimiendo la fraternidad como principio fundamental. A su vez la democracia comunitarista se condice con las definiciones de una visión social de ciudadanía, primando el bienestar y la seguridad en función de la igualdad como fundamento.

\section{Ciudadanía y participación}

Referido a la participación y siguiendo lo dicho por Negri y Hardt, de acuerdo a las formas de organización actual se desprende la relación entre participación y ciudadanía a partir del siguiente trayecto. La multitud, entendida como subjetividades productivas, constituye, a partir del reconocimiento de estas producciones, la emergencia de la identidad, la cual a su vez se materializa en la noción de pueblo. El pueblo representa la identidad de las subjetividades. Por otra parte la nación es la reproducción de estas subjetividades y el Estado la organización institucional de las mismas.

En tanto el punto de inflexión estaría en el momento en que se organiza la producción de subjetividades, este sería el momento y el magma en el cual se desarrolla la organización de la política tradicional, ese es el triunfo de la burguesía.

Hoy la multitud presenta una producción de subjetividades que no responde a las categorías establecidas desde el triunfo de la burguesía (la modernidad), por lo cual organizar estas subjetividades a partir de las categorías pueblo, nación y Estado, y además configurar la participación sobre estos ejes resulta insatisfactorio frente a los deseos de las nuevas subjetividades multitudinarias.

"Se trata de transformar una necesidad impuesta a la multitud -una necesidad que hasta cierto punto fue solicitada por la propia multitud a lo largo de toda la modernidad como una línea de fuga de la miseria y explotación localizada- en una condición de posibilidad de li- 
beración, una nueva posibilidad que se ofrece en este nuevo escenario de la humanidad" (55).

La juventud emerge como la multitud que innova como agente de producción de subjetividades, donde ya no satisfacen las categorías de participación más tradicional, y se encuentran diversas formas de identificación, organización y participación que dan cuenta de lo incompleto de la política tradicional como estructuración de las creaciones de la multitud.

Ahora bien, ¿hacia dónde se encamina este desplazamiento? Por ejemplo, es en el plano de las manifestaciones que se insertan en lo cultural, ocupando la estética, el cuerpo, las artes como elementos políticos. Si bien, el plantear que en el caso de los jóvenes lo cultural se transforma en político, no es una relación proporcional en que todo lo cultural es político, sino que está en cómo se codifique y territorialice esta acción por parte de los jóvenes. Por ejemplo, tomemos en cuenta la visión actual sobre las manifestaciones juveniles que nos remiten esencialmente al caso de las casas okupas.

Con manifestaciones artístico-culturales en las afueras del Centro de Justicia y protestas al interior de la sala se desarrolló la audiencia en la que los seis jóvenes "okupas" detenidos el martes pasado, luego del allanamiento a una casa en que se encontró material para fabricar bombas incendiarias, fueron dejados en prisión preventiva mientras se investiga en un plazo de 90 días su responsabilidad. ${ }^{6}$

Siendo esto, uno de los ejemplos de que estas culturas juveniles al afrontar un problema político no reaccionan desde las significaciones tradicionales, sino que se desplazan a otros códigos, estos nuevos códigos no son interpretables desde la política tradicional, lo que solo es sintetizado en el infiltraje, donde al no conocer las motivaciones y los alcances de estas nuevas formas de reescribir la política, se sindica a los jóvenes con la figura de

6 http://www.lanacion.cl/prontus_noticias/site/artic/20060929/ pags/20060929190926.html 
"infiltrado", dentro de otras, una especie de NN instrumental que sirve al poder político formal para estigmatizar a un segmento de la sociedad que no se manifiesta dentro de los desgastados y deslegitimados caminos de la "política", es decir, ya no se inscriben en los registros electorales, y por consiguiente no votan, y a su vez siendo militantes no obedecen a llamamientos políticos desde las cúpulas, sino que vemos, como es el caso de los estudiantes secundarios, un bricolaje donde confluyen izquierdas y derechas.

\section{Estética como manifestación política "activa"}

La reconfiguración política de la cual hacemos mención, tiene dentro de sus principales dispositivos las manifestaciones estéticas. Desprendido de lo anterior, tenemos que las resistencias estéticas, como una construcción de compatibilidad, que presenta el mundo de las culturas juveniles y más específicamente las re-configuraciones políticas de los jóvenes que se expresan, a nuestro juicio, en elementos estéticos, se inscriben esencialmente dentro de las resistencias del bio-poder como bio-políticas, ya que desde estas matrices es posible sondear las resistencias que van desde las formas de vestir hasta los códigos y significados que otorgan los jóvenes a sus manifestaciones críticas frente a la sociedad actual globalizada, asimétrica, diversa, fluida, que enriquecen el sentir colectivo.

También se hace necesario destacar que cuando apuntamos a transformaciones, revoluciones y/o territorializaciones estéticas, siguiendo a S. Lash, "la lucha por cambiar los códigos de significado en las instituciones y en la actividad social es la lucha principal en el proceso de cambio social del nuevo contexto histórico" (Lash, 2001:198).

En este sentido la labor que ejercen los colectivos en cuestión, apuntaría concretamente a una resignificación estética, la cual se ve reflejada tanto en lo cotidiano del vestir, en pretensiones de impacto social como los graffitis, o singularidades identitarias como los tatuajes. Esta capacidad de procesar símbolos, a la cual 
hace referencia también M. Castells, 1997, es lo que caracteriza y solidifica las posibilidades que proponen los colectivos juveniles.

Esta estética no sólo se inscribe en lo que se refiere al cuerpo como ente de resistencia sino que también al plano urbano en torno a su espacio, el cual está edificado de manera tal que propicia el individualismo (colectivista), esto partiendo de que el esteticismo vanguardista impulsa a partir del espacio la contracción de éste; esto es visible en las metrópolis actuales como Nueva York, Tokio, Londres y ciudades del sur de China:

"del mismo modo que el individualismo democrático en la vida política se convirtió en la impersonalidad mecánica de la burocracia legalracional, y el impulso creativo de las vanguardias estéticas modernistas se convirtió en las casas-cárcel de los bloques de viviendas y los proyectos urbanísticos de los años sesenta" (Lash, 2001:140).

Estas manifestaciones en el plano estético inundan los espacios privados, lo que redunda en el amoldamiento de los sujetos a ellos, como parte de sus pliegues estéticos que fundan su subjetividad. "La proliferación molecular de procesos singulares que transforman irreversiblemente las relaciones de los individuos y de las colectividades en el mundo arterial y en el mundo de los signos" (Guattari, 1995:69), al afectar el mundo cotidiano y de relaciones sociales (sociabilidad), la complejización de estos procesos lleva a que se produzcan transformaciones en el plano político, ya que este ámbito se transforma partiendo de las interrelaciones sociales, y no al revés.

¿Cómo se organiza esa información? Es en el "terreno de la apropiación y reapropiación de la información" (Melucci, 1994: 120), ya que como hemos venido mencionando, la capacidad de montar una acción colectiva está relacionada con la producción de información y el agenciamiento de dicha información. Así su poder real de oposición está en qué tan capaces sean para desarrollar una plataforma que les sea útil y permita emitir información 
constantemente, con la cual (in) formar sus objetivos, y pintar el aire donde se esconde el control social.

Por otro lado, los sistemas de comunicación como la Web, a partir de aquí se crean nuevas sensibilidades entre quienes comparten las mismas inquietudes, necesidades, carencias, y por ello esta herramienta influiría en la conciencia de la sociedad en su conjunto, y en especial del mundo juvenil, que re-territorializa estas líneas y las hace más flexibles para sus manifestaciones micropolíticas.

"Tienen la tarea de rellenar el vacío dejado por las instituciones verticalmente integradas, heredadas de la era industrial (partidos políticos, sindicatos, asociaciones ciudadanas formales)" (Granados, 2003: 18). Así las formas de interrelacionarse de los sujetos pasan a tener nuevos lenguajes, los cuales se constituyen también en nuevas formas de expresión y resistencia política.

"Los nuevos movimientos se construyen en torno a sistemas de comunicación, esencialmente Internet y los medios de comunicación, porque ésta es la vía principal que estos medios encuentran para llegar a aquellas personas que puedan compartir sus valores, y desde ella influir en la conciencia de la sociedad en su conjunto" (Granados, 2003: 18).

Existen también centros que son característicos y que suelen reunir estos dos aspectos, uno de ellos es el de Porto Alegre, donde si bien su invitación versa sobre los problemas de la globalización, la convocatoria no está inscrita dentro de los canales formales de información, por lo cual, para ello se utiliza el mecanismo que hemos mencionado que es Internet, por otro lado se reúnen diversas corrientes estéticas que dan cuenta del individualismo colectivista que fluye en el espacio social y en las formas de interacción, relación y comunicación. "Lo que está cambiando no es el tipo de actividades en las que participa la humanidad, sino su capacidad de utilizar como fuerza productiva lo que distingue a nuestra especie como rareza biológica, su capacidad de procesar símbolos" (MartínBarbero, 2003: 3). 
Esta capacidad de procesar símbolos en el mundo de las culturas juveniles se ubica, o mejor aún son tomadas y procesadas de mejor forma por ellos, dado que manejan los códigos para hacer las lecturas de esos símbolos, y aquí nos referimos a que están mejor socializados con estos nuevos lenguajes, ya que su entendimiento de la realidad ha sido nutrido con los nuevos lenguajes informacionales, y es por ello que están en mejor pie para interpretar las transformaciones culturales actuales, más que otros segmentos de la sociedad.

"La producción de nuevas formas de subjetividad colectiva capaz de administrar, en función de finalidades no capitalistas, las revoluciones informáticas, comunicacionales, robóticas y de producción difusa, no constituyen de ninguna manera una utopía" (Guattari, 1995:68).

\section{El des-orden en la política no tradicional (y tradicional)}

Es pertinente enunciar al infiltrado como un agente que interviene en el organismo, o la estructura por ejemplo de una marcha "social"; cabe hacerse la pregunta: ¿es este infiltrado propio de esa estructura? Habría que señalar en este sentido que las manifestaciones violentas, o anomalías constantes, entendiéndolas como un error sistemático, efectivamente son parte en la conformación de la participación política. Siguiendo con los criterios que propone Aristóteles respecto de la ciudadanía, esta debe ser entendida en el ejercicio (como un "deber hacer") de manifestación de la voz y el voto; es así como expresiones violentas, "antisistémicas", surgen como una forma de expresión del primero de estos atributos. Teniendo consideración que la apreciación del voto se encuentra en una constante devaluación, la cual se sustenta en la desconfianza tanto de la clase política, como de sus métodos, los cuales al parecer, no son del todo efectivos en términos de participación y persuasión sobre la ciudadanía y más aún en los sectores de jóvenes, teniendo como pequeño ejemplo la evolución de la inscripción electoral juvenil. El infiltrado de 
"la marcha social" (construyendo una figura) responde a ciertas características, no se integran en las formas de participación tradicional como gremios, sindicatos o los partidos políticos. Esto tiene que ver con la oposición radical al sistema, lo cual facilita la caricaturización y vinculación directa con lineamientos anarquistas, en un ejercicio de simplificación mediático, en donde las industrias culturales más tradicionales también ejercen su cuota de poder en la orientación de la "opinión pública", sin embargo estas expresiones parecen ser aun más complejas que las de-formaciones que recibimos desde los medios.

En este mismo sentido no se puede desconocer que el "infiltrado" es un agente que también se utiliza desde las estructuras "tradicionales", con la intención de obtener alguna pequeña ventaja práctica en eventos determinados. Como ocurre con los servicios de inteligencia del Estado, para diversos fines anti-delictuales. ¿Por qué no es parodiado este infiltraje? Deberíamos respondernos, que es debido a que es legitimado desde la estructura, orientado a buscar el bien público. Pero, cuando la ética kantiana del imperativo categórico se ve reducida a una "ética mínima de la honestidad" -parafraseando a Lipovetsky-, a valores centrados en el plano conductual de cada individuo, las estratagemas de los media introyectan en la sociedad civil sensaciones que terminan influyendo en las políticas públicas del gobierno.

Como definimos en un comienzo y como queda de manifiesto con lo expuesto, el infiltrado se conforma dentro y para la estructura $u$ organismo, independiente del fin que esta tenga, ya que en términos prácticos el infiltrado se sitúa como una categoría icono de manifestaciones, en tanto más radicales por ser "violentas" contra el Estado y la propiedad privada, por tanto rompen el bien público, lo categórico, y la propiedad privada. Con lo anterior, se desarrolla la deslegitimación de las manifestaciones políticas "infiltradas" y no se aceptan desde la imagen y de la significación del infiltrado; esta situación se da también en los que critican al modelo de estructura, pero desde la participación 
"política" ciudadana de la sociedad civil, que es el lugar donde se posiciona al infiltrado, pero además en espacios no tradicionales como el del hincha o el recital, donde su figura cambia de ser un sujeto particular, a la confusión con la manada, "el lumpen".

\section{Bibliografía}

Aristóteles. Política, Libro tercero, Del Estado y del ciudadano. Teoría de los gobiernos y de la soberanía. Del reinado. Capítulo I Del Estado y del ciudadano, en: http://ar.geocities.com/proyectoinacayal/cuerpo_BibliotecaInacayal.html

Castels, Manuel (1997). Local y global. La gestión de las ciudades en la era de la información. Madrid: Taurus.

Cohen, Jean y Arato, Andrew (2000). Sociedad Civil y Teoría Política. México D.F.: FCE.

Granados, Ignacio Martín (S.F.). El proceso de construcción de la participación ciudadana a través de canales institucionales. Un estudio de caso: Segovia, en http://www.aecpa.es/archivos/ congresos/congreso_07/area04/GT14/MARTIN-GRANADOS-Ignacio(UCM).pdf

Guattari, Félix (1995) (traducción Paul Baines, Julian Pefanis; edición original en francés 1992) Chaosmosis. An ethico-aesthetic paradigm, Indiana University Press, Bloomingdale-Indianapolis.

Hardt, Michael y Negri, Antonio (2002). Imperio (Buenos Aires: Paidós). Edición original: Empire (Cambridge, Mass.: Harvard University Press, 2000).

Lash, Scott (2001). Critique of Information. Sage, Londres.

Lipovetsky, Gilles (1996). La era del vacío, Ensayos sobre el individualismo contemporáneo. Anagrama, Barcelona.

Marshall, T.H. (1949) Ciudadanía y clase social. Reis 79/97.

Melucci, Alberto (1994). Asumir un compromiso: identidad y movilización en los movimientos sociales», Zona Abierta, 153-180.

Mouffe, Chantal (1999). El retorno de lo político. Paidós, Buenos Aires.

Martín-Barbero, J. (2003). Oficio de cartógrafo. Travesías latinoamericanas de la comunicación en la cultura, Fondo de Cultura Económica, Bogotá. 